\title{
The Network Structure of the Forestry Research as a Scientific Field in Turkey between 1999 and 2019
}

\author{
Hamid Dervis ${ }^{1}$, Sezgin Ayan ${ }^{2 *}$
}

(1) Kastamonu University, Faculty of Science and Literature, Department of Information Management \& Records, Kuzeykent Campus, TR-37100 Kastamonu, Turkey; (2) Kastamonu University, Faculty of Forestry, Silviculture Department, Kuzeykent Campus, TR-37100 Kastamonu, Turkey

* Correspondence: e-mail: sezginayan@gmail.com
Citation: Dervis H, Ayan S, 2021. The Network Structure of the Forestry Research as a Scientific Field in Turkey Between 1999 and 2019. South-east Eur for 12(1): 57-66. https://doi. org/10.15177/seefor.21-02.

Received: 30 Sep 2020; Revised: 24 Nov 2020; 27 Dec 2020; Accepted: 13 Jan 2021; Published online: 11 Feb 2021

\begin{abstract}
This study aims to analyse and map the network structure of the scholarly communications in the realm of forestry research between 1999 and 2019 in Turkey using bibliometric analysis and social network analysis methods of the articles published within Clarivate Analytics' Web of Science (WoS). A total of 8689 records, including their bibliographic data, were extracted from WoS. The analysis of each sub-period shows that the number of international collaboration of Turkish authors has increased globally from 23 countries in the first sub-period to 113 countries in the last sub-period within forestry publications. Also, the annual percentage rate of publications has increased from 58 articles in 1999 to 1016 in 2019 in the realm of forestry alongside with their received average citations in each sub-period. Multi-author articles precede singleauthor articles in the field of forestry in each sub-period. This research is the first analysis of forest research production using bibliometric and network analysis in Turkey. According to the results biomass, remote sensing and climate change were current trends on forest research in Turkey. Incidentally, the research findings can be used by policymakers regarding future investments in forestry research development.
\end{abstract}

Keywords: bibliometric; social network analysis; forestry publication; forestry science mapping

\section{INTRODUCTION}

Forestry education in Turkey has a long history. Technical training and education in forestry began with the establishment of the first Forestry School in Istanbul, on $17^{\text {th }}$ November 1857 (Gumus 2016), which became the first Faculty of Forestry under the Istanbul University (IUFF) in 1948 (Ozdonmez and Ekizoglu 1996, Ekizoglu 2001). From the point of view of the country, the primary objective of the forestry education at the beginning was to train human resources for the forestry organization. The second Forestry Faculty of the Black Sea Technical University was started and specialized in forest industry after its establishment in 1971. After 1993, 10 more new forestry faculties were established in different regions in Turkey (Yurdakul Erol and Sahin 2016). Four specialization fields at bachelor level education, which are forest engineering, forest industry engineering, wildlife management and landscape architecture, have been established. Graduate studies are provided under more than 20 different programs presently.

The priority-setting problem in forestry research projects in Turkey has been an important issue mainly since 1994, when the Forestry Research Master Plan (FRMP) was prepared as a part of the Turkish Agricultural Research Project (TARP) supported by the World Bank. Usually a monetary analysis is conducted to assess research output (Dasdemir 2005). The majority of current forestry research projects in Turkey are proposed, funded and carried out by the MAF and its 13 Forestry Research Institutes (FRIs) and scientific research funds of universities and the scientific and technological research council of Turkey (TUBITAK). Furthermore, the activities of well-established nongovernmental organizations such as Chamber of Forestry Engineers, The Foresters' Association of Turkey etc., have contributed to the scholarly communications of the forestry sector. 
Admittedly, as well as an increase in the number of forest faculties in Turkey, the objectives they pursue are diversified and proliferated in need of the day. The function of forest faculties is no longer limited to education of professionals for forestry management and organization; their function now includes producing information, raising public awareness, supporting sustainable development, and playing an effective role in the formation of related policies. On the other hand, following the change in the science of forestry education, Turkey and the rest of the world have adapted to the changing needs and priorities in forestry and forestry direction, which has provided dynamism in Turkish forestry education (Erdas 2008). Particularly, Bologna Process including Turkish Higher Education has been effective on the renewal and reorganization of the curriculum of the program since the beginning of 2000 s. In Turkey, research topics, publications, and scientific events such as conferences, symposia, and congresses of the world directly affected forestry and environmental policies. Periodically, biodiversity, combating desertification, sustainability, participatory management, ecosystem-based planning, climate change, climate change mitigation and migration have been the dominant themes.

In the last few decades, the attention to the scientific productivity of researchers and research institutions in the world has increased (Abramo and D'angelo 2014). Similar to other scientific fields, Chirici (2012) reported two main approaches for evaluating scientific productivity for forestry development in Italy: (i) peer review, a qualitative evaluation in which a group of experts evaluates the research output, and (ii) bibliometric evaluation, where quantitative analysis of publications and citations is performed.

Evaluation of researchers' work and careers has increasingly transitioned from peer review to bibliometric evaluation (Rogers 2002, Cameron 2005). Bibliometric analysis, along with its gradual widening of applications, plays a significant role in finding scientific indicators for policy-makers and the executive branch. Pritchard (1969) defined bibliometric studies as a quantitative analysis of written publications by using statistical and mathematical applications. Similar to other scientific fields, forestry is studied by data scientists to measure its performance in terms of growth, structure, productivity, and interrelationship.

Hazarika et al. (2003) in a bibliometric analysis conducted in India based on the journal The Indian Forester for the period between 1991 and 2000 stated that multiple authorship was dominant (64.6\%). Miah et al. (2013) conducted a bibliometric analysis of forestry research (1977-2007) in Bangladesh and established a strong increase of forestry papers from 1998 to 2000, but they started to decrease in 2001 and again increased in 2005 due to various factors. Most of the published papers were multi-authored in a bibliometric analysis of forestry researchers in Tanzania, and the majority (88.1\%) of the publications were multiple-authored (Sife et al. 2013). There are some studies on forestry publications from bibliometric viewpoint: covering bibliometric analysis of global forest ecology (Song and Zhao 2013), co-term and citation analysis of evolution of Mediterranean forest research (Nardi et al. 2016), bibliometric productivity of forest scientists in Italy
(Giannetti et al. 2016), bibliometric analysis of Open Access forestry research (Peiró 2018).

On the other hand, social network analysis (SNA) is a method derived from sociology to measure network structure (Otte and Rousseau 2002). SNA conceptualizes social structure as nodes and links connecting these nodes. Moreover, SNA quantifies the relationships between nodes within a network structure. Anthropologists, psychologists, sociologists, physicists, economists, and mathematicians utilize social network analysis methods to measure the relationship between people, organizations, or even nations. For example, Jacob L. Moreno (1934), a psychologist who mapped the social interaction of elementary school children, was instrumental in spreading the SNA methodology in scientific research. He named his map sociogram. SNA utilizes sociogram and mathematical graph theory to analyse the network structure (Scott 2000), where a sociogram shows the interaction among people within a group. One of the models within SNA is a smallworld phenomenon that indicates each node (actor) in a random network structure which is connected to another node through an acquaintance (link) (Milgram 1967).

Literature defines co-authorship as a collaboration of two or more scientists in a research activity. Rogers (2003) stated that social interactions in multidisciplinary scientific areas and practitioners are instrumental in disseminating knowledge. Co-authorship among authors in the field of forestry reveals the network's indicators within each period, which is instrumental in diffusion of knowledge inside the scientific endeavour. Bibliometric methods such as cooccurrence have been utilized to conduct social network analysis; for example, co-word analysis (Leydesdorff and Vaughan 2006), maps of the collaborators (Wagner and Leydesdorf 2005) and co-authorship (Glanzel 2002) were applied to create social network structure of scientific collaboration among universities. Romanelli and Boschi (2019) for instance used Science Citation Index Expanded within online WoS database to measure the legacy of Elinor Ostrom on common forest research using bibliometric and network analysis methods. They used the co-occurrence of words to map the cognitive development in the network formation. Besides, Romanelli and Boschi utilized VOSviewer (Van Eck and Waltman 2010) to undertake the task.

Although there are numerous articles exploring forestry as a research field using bibliometric analysis (Song and Zhao 2013, Nardi et al. 2016), limited studies have been focused on social network analysis of the subject domain (Giannetti et al. 2016). This study explores forestry research development at the macro and micro levels in Turkey using bibliometric and SNA techniques.

\section{MATERIALS AND METHODS}

To delineate records properly, we used the "thesaurus "of Forestry Compendium CAB Abstracts database to define the search terms. We extracted terms from CAB Abstracts thesaurus based on the word "forestry," including their narrower terms and related terms. With the help of an expert in the forestry field, we finalized a compound text query (See Appendix A). 
To conduct the research (Retrieved 24.12.2020), a total of 8689 records from Science Citation Index Expanded (SCl/ EXPANDED) of all document types in all languages were downloaded from Web of Science (WoS) Clarivate Analytics (online academic database) using a compound text query between 1999 and 2019, having at least a country/regional Turkish collaborator. Clarivate Web of Science (WoS) was selected as a database covering inclusively referred journals. WoS was selected as a database since it covers inclusive referred journals. Descriptive analysis and bibliometric analysis were used to evaluate scholarly communications within forestry journals in WoS. According to WoS, scientific publications gained momentum starting in the past two decades; we chose 1999 as the starting year and divided the last two decades into four periods to gradually monitor research development.

The total record was divided into four sub-periods (19992003, 2004-2008, 2009-2013 and 2014-2019). Descriptive analysis was conducted using Bibliometrix (Aria and Cuccurullo 2017), an $R$ package was used to create and to compare indicators for each period. Secondly, Bibexcel was used to make co-occurrence frequency matrix from bibliographic data extracted from WoS (Persson et al. 2009). VOSviewer was used to map the co-occurrence analysis. Gephi (Bastian et al. 2009) software analysed the network's properties within scholarly communication in the field of forestry.

The social network analysis approach presents scientific collaboration in the field of forestry research. SNA conceptualizes the network structure using centrality measures in terms of betweenness, closeness, and degree. Betweenness centrality measures a node's ability to connect other nodes in the network, whereas closeness centrality measures how fast a node can access another node in the system. Degree centrality measures the number of connections a node has with other network structure nodes (Scott 2000). The clustering coefficient indicates an inclination to aggregate a subgroup within a group (Newman 2001). Using SNA and descriptive analysis mentioned above, we have addressed the following research questions for the network structure of the forestry in Turkey: (i) Does the flow of knowledge in the network structure depict growth in publications' rate?, (ii) Which of the most prolific universities are publishing in the forestry research field, thus stimulating knowledge diffusion?, (iii) What are the research topics within forestry?, (iv) Who are the prolific authors, and do they collaborate more frequently? (v) What does network structure look like?

\section{RESULTS}

Research questions have been answered as follows:

(i) Does the flow of knowledge in the network structure depict growth in publications' rate?

A total of 8702 articles were extracted from WoS from 1999 to 2019. Description analysis is shown in Table 1. The number of records, average citation per article, the total number of authors, authors of single-authored articles, authors of multi-authored articles, authors per item, and coauthors per reports have increased for each sub-period, except for average citations per document and annual percentage growth rate.

For instance, the total average citation decreased from 33.73 in 1999-2003 to 28.68, 20.91, and 9.31 in other three periods respectively. Although the total number of articles has grown steadily from 371 in the first period (1999-2003) to 4020 in the last period (2014-2019), the annual percentage growth rate for each period fluctuates between $19.93 \%$ and $19.30 \%$, and $3.07 \%$ and $12.82 \%$, respectively (Table 1 ). These results confirm that the increasing number of research institutions in Turkey in the last three decades have triggered the number of researchers and the number of articles.

Figure 1 shows that the number of publications has increased from 58 articles in 1999 to 1016 articles in 2019, and about eighteen folds in the scholarly publications in the realm of forestry. A steady increase in the number of articles has been determined. The study findings indicate that forestry researchers in Turkey produced an average of 414.4 articles per year between 1999 and 2019.

(ii) The next question to be answered is which of the most prolific universities are publishing in the forestry research field, thus stimulating knowledge diffusion?

Table 2 shows the aggregated publications produced by the 15 most productive universities, producing 275,875 , 2004, and 2247 articles, which yields 74\%, 67\%, 66\%, and

Table 1. Descriptive analysis of articles for each period.

\begin{tabular}{|c|c|c|c|c|}
\hline \multicolumn{5}{|c|}{ Descriptive Analysis } \\
\hline Period & $1999-2003$ & 2004-2008 & 2009-2013 & 2014-2019 \\
\hline Documents & 371 & 1294 & 3017 & 4020 \\
\hline Ave citations per docs & 33.73 & 28.68 & 20.91 & 9.31 \\
\hline Authors & 866 & 2791 & 7301 & 15420 \\
\hline Authors of single-authored docs & 47 & 143 & 322 & 376 \\
\hline Authors of multi-authored docs & 830 & 2648 & 6979 & 15044 \\
\hline Single-authored docs & 69 & 219 & 415 & 438 \\
\hline Authors per docs & 2.36 & 2.16 & 2.42 & 3.8 \\
\hline Co-Authors per docs & 2.94 & 3.26 & 3.82 & 5.37 \\
\hline Annual percentage growth rate & $19.93 \%$ & $19.30 \%$ & $3.07 \%$ & $12.82 \%$ \\
\hline
\end{tabular}


1200

1000

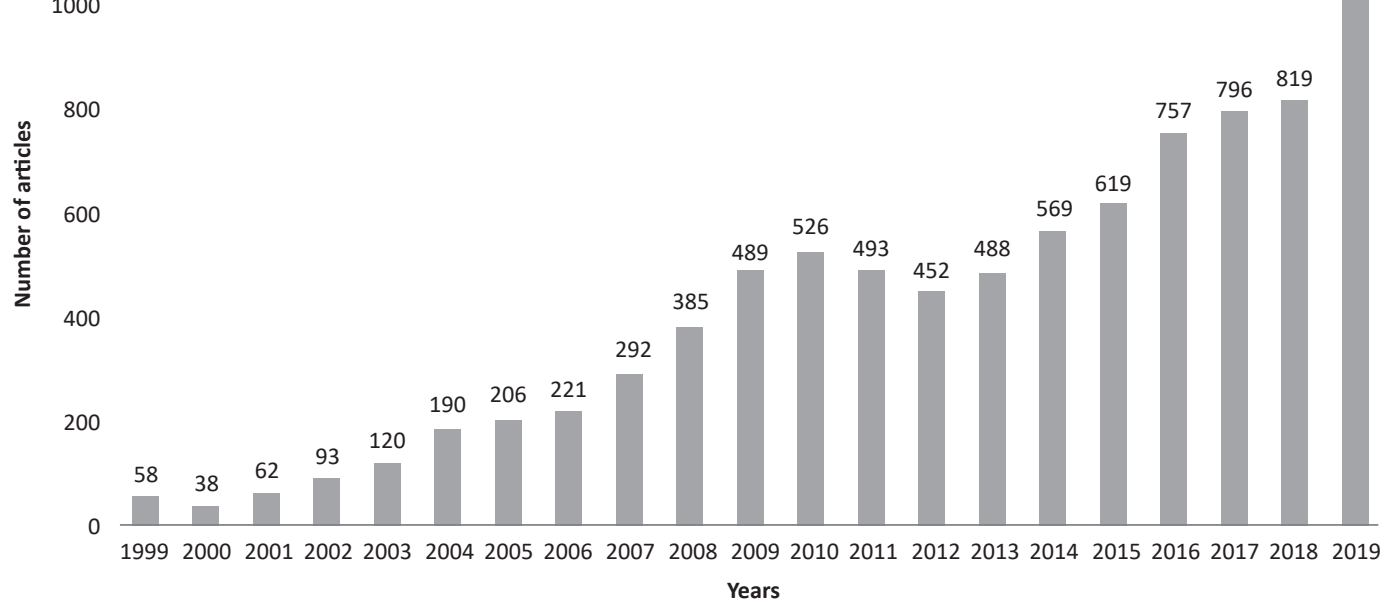

Figure 1. Number of publications in forestry: 1999-2019.

$56 \%$ of scholarly publications in each sub-period respectively. As seen in Table 2, the 15 most productive universities in forestry scientific publications increased in each subsequent period. It was determined that Istanbul University and Karadeniz Technical University, the oldest forestry faculties in Turkey, were the most productive universities in terms of the publication number in the four subsequent periods. Although almost the same prolific universities appear in each sub-period with some fluctuation, for example, Bulent Ecevit University appears in the first and second sub-period, it has lost its position in the third and fourth sub-sequent period. This is because after 2007 Bartin Faculty of Forestry separated from Bulent Ecevit University and continued its academic life as an independent university under the Bartin University. Bartin University appears in the third and fourth periods at $12^{\text {th }}$ and $7^{\text {th }}$ rank respectively. Similarly, Kahramanmaras Sutcu Imam University appears in the first, second, and third sections respectively; however, it does not appear in the last period.

Kastamonu University, in terms of the number of publications in the last period, ranked $6^{\text {th }}$ with a total number of 131 articles. Until 2006, the Kastamonu Forestry faculty continued its academic activities as a faculty affiliated with Gazi University.

With 41 publications within 1993-2003, Istanbul University is followed by Karadeniz Technical University with 134 publications for 2004-2008. Concurrently, Istanbul University succeeded with 295 scientific publications for 2009-2013 and 263 for 2014-2019. Although there are no forestry faculties or forestry research institutions, it can be seen from Table 2 that publications related to forestry are produced at universities such as Ege University, Middle East Technical University, Hacettepe University, Istanbul Technical University, and Yildiz Technical University, which indicates the multidisciplinary nature of the research development in the realm of forestry in Turkey. (iii) What are the research topics within forestry?

VOSviewer calculated and created the keywords' cooccurrence from bibliographic data with a minimum threshold of 2 occurrences of the keywords. One can say that the network structure consists of 7 clusters where each cluster is made of distinct keywords. The links between nodes indicate the strength of co-occurrence of words between clusters. As it can be seen in Figure 2, biomass with the highest centrality is located in the centre of the graph, followed by pyrolysis and supercritical fluid extraction in the upper left side of the network. Within the second sub-period (2004-2008), the total number of keywords increased to 477 , with a minimum of 2 occurrences of each keyword, making 25 clusters. In this period, remote sensing and mechanical properties are centralized, and logging, accumulation, hidden Markov models are periphery. Parallel to growth in publications during the 2009-2013 sub-period, the total number of keywords has increased to 1243 with the same criteria mentioned for the previous periods. Although remote sensing still stands with the highest centrality located in the centre of the network of the graph, biodiversity, climate change, and recycling started to appear within the network structure. Finally, climate change has become the latest research topic in the last sub-sequence.

(iv) Who are the prolific authors, and do they collaborate more frequently?

The answer to the question of who the prolific authors are, and whether they collaborate more frequently is depicted in Figure 3, which indicates a productive university generating prolific authors. The 10 most productive authors in each subperiod are also shown in Figure 3. Although some authors are present in each sub-period, most of them do not repeat in different sub-periods. For example, a few authors appeared in the first and second sub-period, and one appeared in the third and fourth sub-period in the same location, with over fifty publications (Figure 3). 
Table 2. Top 15 Turkish universities with highest number of publications in each sub-sequence.

\begin{tabular}{|c|c|c|c|c|c|c|c|c|c|c|}
\hline $\mathbf{N}$ & \multicolumn{2}{|c|}{ 1999-2003 } & \multicolumn{2}{|c|}{ 2004-2008 } & \multicolumn{3}{|c|}{ 2009-2013 } & \multicolumn{3}{|c|}{ 2014-2019 } \\
\hline 1 & \multicolumn{2}{|c|}{ Istanbul Uni. (41) } & \multicolumn{2}{|c|}{ Karadeniz Tech Uni. (134) } & \multicolumn{3}{|c|}{ Istanbul Uni. (295) } & \multicolumn{3}{|c|}{ Istanbul Uni. (263) } \\
\hline 2 & \multicolumn{2}{|c|}{ Karadeniz Tech Uni. (39) } & \multicolumn{2}{|c|}{ Istanbul Uni. (127) } & \multicolumn{3}{|c|}{ Karadeniz Tech Uni. (214) } & \multicolumn{3}{|c|}{ Istanbul Tech Uni. (260) } \\
\hline 3 & \multicolumn{2}{|c|}{ Istanbul Tech Uni. (37) } & \multicolumn{2}{|c|}{ Istanbul Tech Uni. (91) } & \multicolumn{3}{|c|}{ Istanbul Tech Uni. (191) } & \multicolumn{3}{|c|}{ Karadeniz Tech Uni. (232) } \\
\hline 4 & \multicolumn{2}{|c|}{ Hacettepe Uni. (27) } & \multicolumn{2}{|c|}{ Bülent Ecevit Uni. (62) } & \multicolumn{3}{|c|}{ Suleyman Demirel Uni. (161) } & \multicolumn{3}{|c|}{ Middle East Tech Uni. (178) } \\
\hline 5 & \multicolumn{2}{|c|}{$\begin{array}{l}\text { Kahramanmaras Sutcu } \\
\text { Imam Uni. (21) }\end{array}$} & \multicolumn{2}{|c|}{ Gazi Uni.(54) } & \multicolumn{3}{|c|}{ Ege Uni. (149) } & \multicolumn{3}{|c|}{ Suleyman Demirel Uni. (147) } \\
\hline 6 & \multicolumn{2}{|c|}{ Ankara Uni. (19) } & \multicolumn{2}{|c|}{ Selcuk Uni. (54) } & \multicolumn{3}{|c|}{ Duzce Uni. (134) } & \multicolumn{3}{|c|}{ Kastamonu Uni. (131) } \\
\hline 7 & \multicolumn{2}{|c|}{ Middle East Tech Uni. (16) } & \multicolumn{2}{|c|}{ Ankara Uni. (52) } & \multicolumn{3}{|c|}{ Middle East Tech Uni. (122) } & \multicolumn{3}{|c|}{ Bartin Uni. (129) } \\
\hline 8 & \multicolumn{2}{|c|}{ Akdeniz Uni. (|12)| } & \multicolumn{2}{|c|}{ Hacettepe Uni. (51) } & \multicolumn{3}{|c|}{ Gazi Uni. (112) } & & e Uni. & \\
\hline 9 & Dol & & Kahram & ham & Kahram & $\begin{array}{l}\text { as Sutcu Ir } \\
104)\end{array}$ & & Yild & ech Un & \\
\hline 10 & & & & & $\mathrm{Hac}$ & Uni. (99) & & & ova Uni & \\
\hline 11 & & & Middle E & $(45)$ & & Jni. (97) & & $\mathrm{Hac}$ & epe Un & \\
\hline 12 & & & Sulym & & & ni. (90) & & & i Uni. ( & \\
\hline 13 & Ond & (9) & & & Ministry o & $\begin{array}{l}\text { try Water } \\
\text { ey (86) }\end{array}$ & ffairs & & ra Uni. & \\
\hline 14 & Bul & & Abant & & Dok & I Uni. (77 & & & Uni. (I & \\
\hline 15 & & & & & & Uni. (76) & & Mugla S & $\mathrm{Kocm}$ & i. (95) \\
\hline & (N) & (\%) & (N) & (\%) & $(\mathrm{N})$ & (n) & (\%) & $(\mathrm{N})$ & (n) & (\%) \\
\hline & 371 & 74 & 1294 & 67 & 3017 & 2004 & 66 & 4020 & 2247 & 56 \\
\hline
\end{tabular}

Note: Number in the parenthesis shows the total number of publications at each university in each sub-period. (N): Corresponds to the total of publications in each sub-period; $(n)$ : Corresponds to the sum of publications by the 15 most productive universities in each sub-period, and (\%): Corresponds to the percentage of publications bv the 15 most productive universities each sub-period.

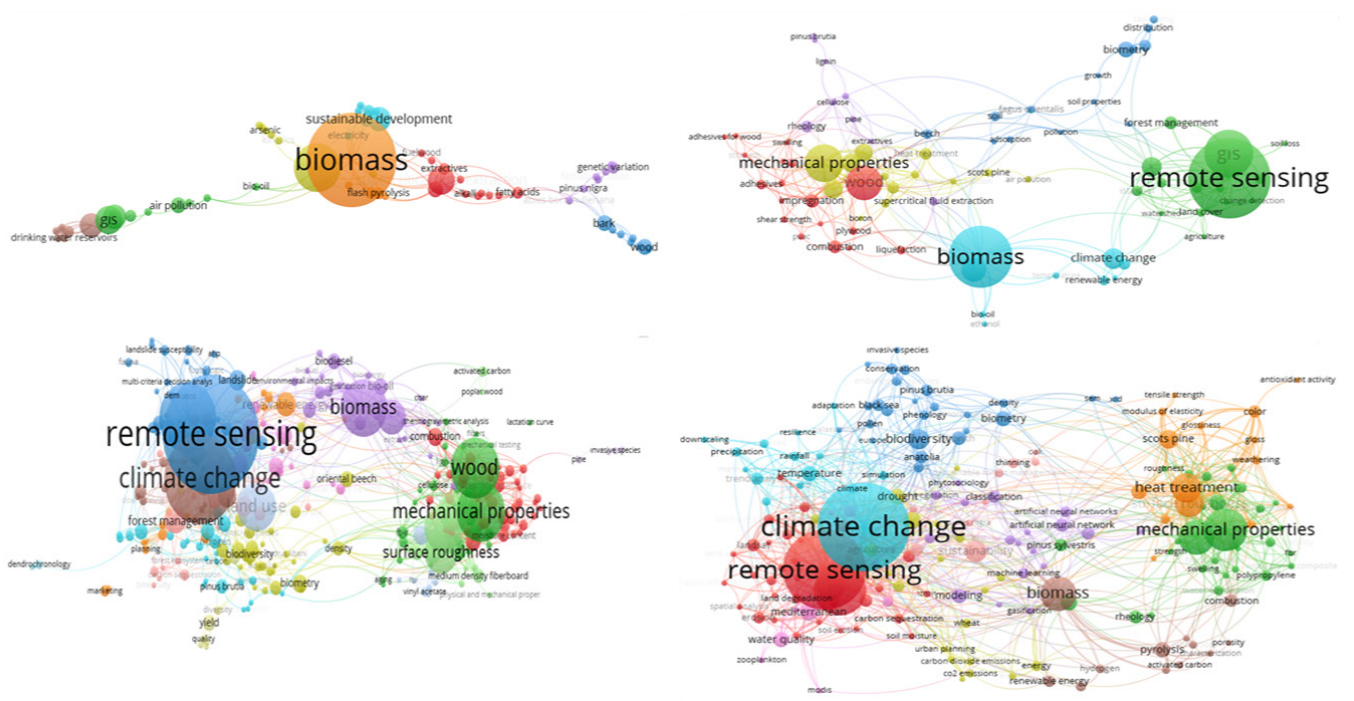

Figure 2. Keyword co-occurrence: 1999-2003 (upper left), 2004-2008 (upper right), 2009-2013 (lower left), $2014-2019$ (lower right). 
(v) Finally, what does network structure look like?

Degree centrality coefficients rose slightly from 0.027 in 1999-2003 to 0.033 in 2004-2008, and 0.059 in 2009-2013, but to some extent dropped marginally from 0.059 in 20092013 to 0.047 in 2014-2019 sub-periods, correspondingly. The number of authors increased in each period; the betweenness centrality increased slightly in each period from 0.00098 to 0.104 , which means that the growth in publications within the second sub-period affected the flow of information among authors, resulting in higher betweenness centrality. However, high closeness centrality coefficients indicated the over $50 \%$ of sub-networks within the whole network are connected. Besides, growth in the clustering coefficients in each period is an indication of the small-world phenomenon in the network structure (Table 3).

VOSviewer calculated the total strength of the coauthorship link for each selected country with a threshold of one number of the article for each subsequence. For instance,

\section{Most productive Authors}

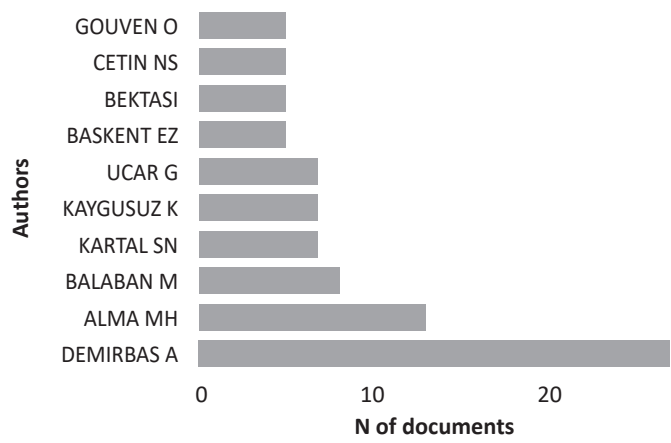

\section{Most productive Authors}

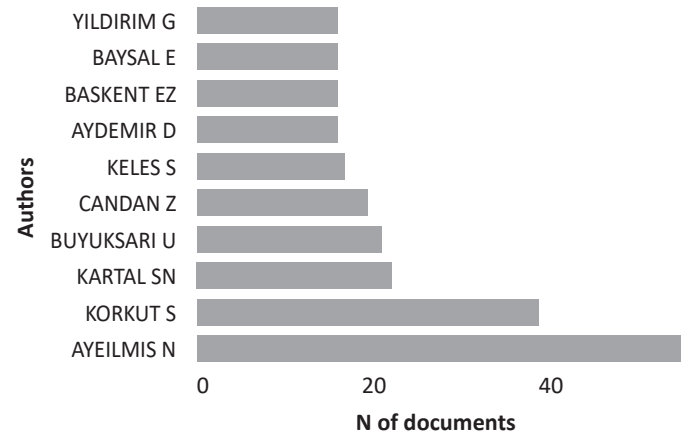

Turkish researchers in the field of forestry collaborated with 23 countries during the first sub-period; in Figure 4, international collaboration is depicted as a center-periphery network structure. Similarly, Turkish scientists in the realm of forestry as in the first sub-period collaborated with the United States of America, the United Kingdom and Wales on the one hand, and Slovenia, Germany, Belgium and Finland on the other, located in the left of the network close to the center, too. However, Italy, the Czech Republic and Japan are located in the periphery of the network. The total number of collaborates raised three folds from 23 to 69 in just five years. New collaborations have entered the network - Denmark, New Zealand, India in the same cluster close to the center; Russia, Bulgaria, Sweden, Jamaica, and Egypt are nearer to center then Finland, which is located in the periphery. Compared to the previous period, slightly increased network in the third sub-period from 69 to 84 resulted in new collaborations with countries.

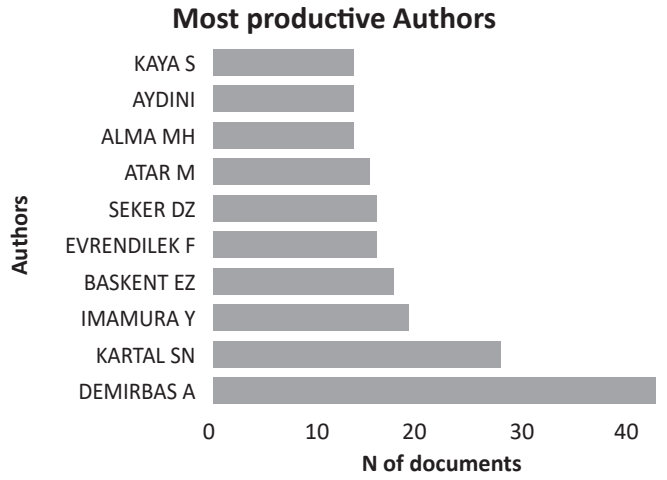

Most productive Authors

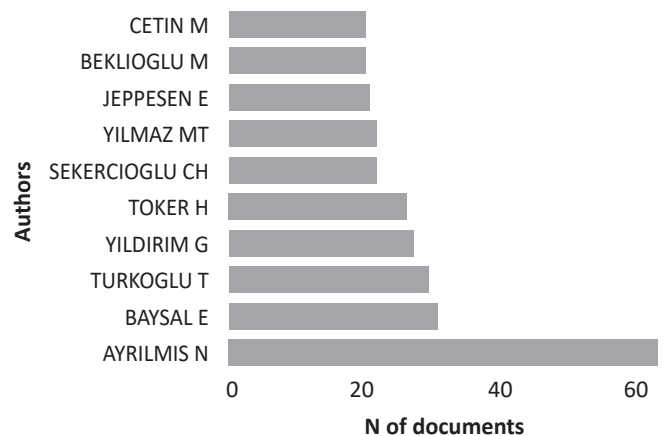

Figure 3. The most productive authors in each sub-sequence: 1999-2003 (upper left), 2004-2008 (upper right), $2009-2013$ (lower left), 2014-2019 (lower right).

Table 3. Network measures of forestry in each sub-sequence.

\begin{tabular}{ccccc}
\hline & $\mathbf{1 9 9 9 - 2 0 0 3}$ & $\mathbf{2 0 0 4 - 2 0 0 8}$ & $\mathbf{2 0 0 9 - 2 0 1 3}$ & $\mathbf{2 0 1 4 - 2 0 1 9}$ \\
\hline Degree centrality & 0.027 & 0.033 & 0.059 & 0.047 \\
Betweenness & 0.00098 & 0.067 & 0.117 & 0.104 \\
Closeness & 0.606 & 0.879 & 0.553 & 0.546 \\
Clustering coefficient & 0.284 & 0.221 & 0.265 & 0.301 \\
\hline
\end{tabular}



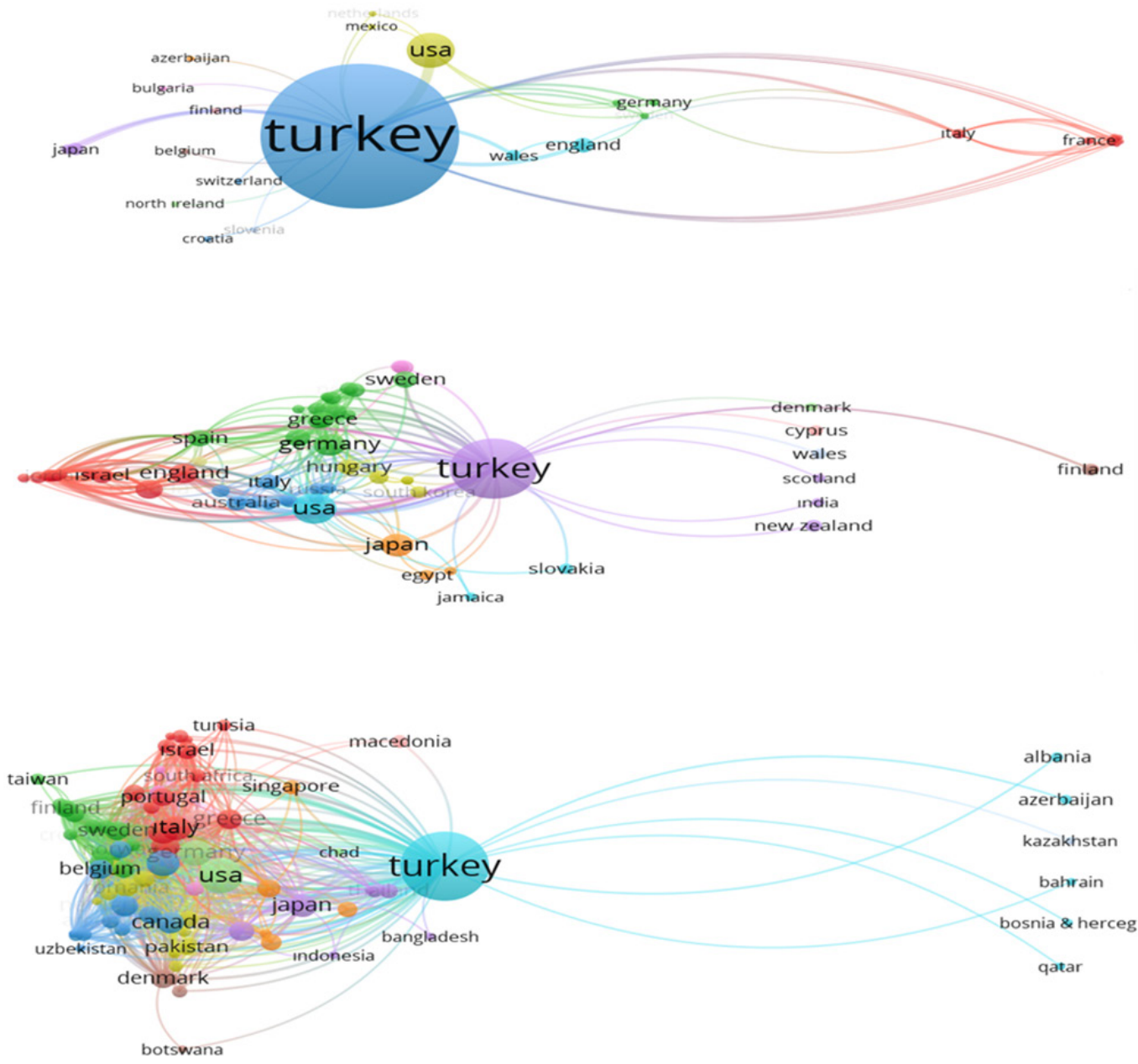

ethiopia

honduras

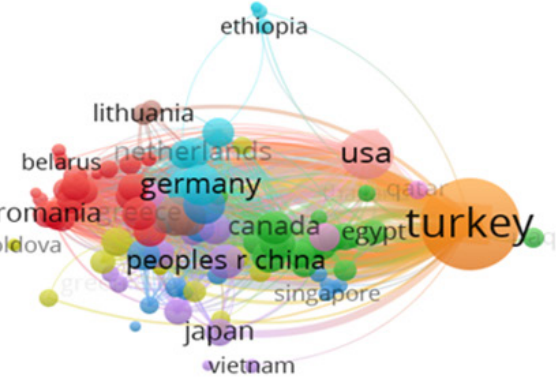

sue a

Figure 4. Number of international collaborations with Turkey in each period from top to bottom: 1999-2003, 2004-2008, 2009-2013, 2014-2019. 
For example, a broad spectrum of countries from the African continent, such as Botswana, Morocco, Algeria, and from the Middle East, such as Iran, Saudi Arabia and Lebanon, as well as Albania, Chile, The People's Republic of China, Serbia, and, finally from central Asian countries (Kazakhstan, Azerbaijan) are new international collaborators, only a few to name. The highest collaborations in the last subperiod reached 113 countries. It can be seen that there are candidates from almost each continent participating in the network collaboration (Figure 4). It can be conjectured that as scientific collaborations have increased, the number of publications has increased too. Therefore, there is a positive correlation between scientists' collaboration and growth in publications internationally and locally.

\section{DISCUSSION}

According to Giannetti et al. (2016), the total number of scientific papers of forestry research employs $0.06 \%$ of the whole scholarly publications worldwide. Measuring research strength is considered essential for a modern country's ongoing innovative and competitive capacity at the global level. A country's success in science, technology, and research determines its ability to compete for increasingly mobile resources and investment capital and to participate in global knowledge-sharing networks (Anonymous 2006). In this context, it can be say that in forestry, being one of the scientific fields, scholarly communication has been booming since 1999 in Turkey. WoS's retrieved data revealed that international collaboration in co-authorship is a fastgrowing research activity in forestry as a research field in Turkey (Figure 3). To start with, 23 countries with a minimum of one co-authorship on an article raised to 113 countries in 2014-2019 in Turkey. The growth in scientific collaboration has increased in the past decade. According to Elsevier (2013), the rate of co-authorship among different countries increased from $14 \%$ in 2003 to $17 \%$ in 2011 . Especially, during the third period (2009-2013), Turkey's development of more intensive cooperation with countries from Central Asia, Middle East and Africa also affected the cooperation in academic publications. Furthermore, after the 2010s, young researchers with language competence who have completed their master's and doctorate studies abroad, especially in the USA and the UK, have returned to Turkey and achieved momentum both in producing international publications and in developing international cooperation (Cetinsaya 2014). Geographical proximity is not an obstacle to collaborative studies among scientists. According to WoS, the number of scientific publications has increased steadily; the number of average citations has gradually shrunk in each sub-period. However, the overall citations have increased from 1999 to 2019. Nevertheless, further studies are needed to determine the extent to which the cited articles are either purely local or international. Topical analysis using co-word analysis indicated that cognitive development started with biomass at the beginning, and eventually changed to remote sensing, biodiversity and climate change in the second and third sub-sequence, and to climate change in each subsequence.
Properties of the network structure of scholarly forestry papers authored by Turkish scientists between 1999 and 2019 indicate that the degree of collaboration at the international levels gradually increased in each period (Figure 4). The number of nodes in the network has increased steadily in the second and third period (1999$2003,2004-2008$ ), yet the network is not well connected. The centrality coefficients of the network structure revealed that sub-clusters within the social network structure are more connected at the micro-level than that at the macro level. The betweenness coefficients' centrality remained low in each sub-period, whereas the closeness centrality increased in each period. The closeness centrality stayed above almost $50 \%$ in all sub-periods, which is an indication of the small-world phenomenon in the network structure. There was a $90 \%$ increase in the number of publications compared to the third period (2009-2013). The increasing number of publications in the fourth sub-period (20142019) shows the concrete repercussions of the academic incentive application implemented in 2016 by Higher Education Council (YÖK) and changes in academic upgrade criteria made by the Inter-University Council (UAK).

\section{CONCLUSIONS}

The results are of major importance for determining Turkey's higher education strategies in the field of forestry, quality management and key indicators. In addition, the research findings can be used by policymakers regarding future investments in forestry development.

\section{Appendix A}

Terms mentioned below were extracted from CAB Thesaurus within Forestry Compendium, a comprehensive, encyclopaedic resource for forestry information. The co-author, an expert in forestry, reviewed and selected the words finally for correctness.

"agroforestry" OR "community forestry" OR "farm forestry" OR "forest policy" OR "private forestry" OR "seed orchards" OR "silviculture" $O R$ "social forestry" $O R$ "urban forestry" $O R$ "afforestation" OR "amelioration of forest sites" OR "amenity forests" OR "amenity value of forests" OR "artificial regeneration" OR "controlled burning" OR "coppicing" OR "degraded forests" $O R$ "demonstration forests" $O R$ "dendrochronology" OR "disturbed forests" OR "farm woodlands" OR "felling" OR "fire detection" OR "fire prevention" OR "fire suppression" OR "forest administration" $O R$ "forest economics" $O R$ "forest inventories" $O R$ "forest management" OR "forest plantations" OR "forest products" OR "forest railways" OR "forest taxation" OR "forestry development" OR "forestry engineering" OR "forestry law" OR "forestry machinery" OR "forestry practices" OR "forestry workers" OR "forests" OR "fuel appraisals" $O R$ "fuel plantations" $O R$ "increment" $O R$ "irrigated stands" OR "linear plantations" OR "logging" OR "mensuration" OR "national forests" OR "pollarding" OR "primary sector" OR "protection forests" OR "protection of forests" OR "pulpwood production" OR "reserved forests" OR "selection forests" OR "silvicultural systems" OR "stand improvement" OR "state forests" OR "stumpage value" OR "wood") "forest ecosystem" OR "forest 
planning" OR "sustainable forest" OR "participatory forestry" OR "forest harvesting" OR "Climate change" OR "assisted migration" OR "forest biodiversity" OR "Mediterranean forest" OR "conservation forestry" OR "reforestation" OR "desertification" OR "forest restoration" OR "forest rehabilitation" OR "fast growing species" OR "natural regeneration" OR "non-wood forest products" OR "biomass production" OR "forest fire" OR "timber production" OR "soil conservation" $O R$ "forest certification" $O R$ "Silva pastoral systems" OR "forest regeneration methods" OR "coppice forest" OR "high forest" OR "provenances trials" OR "introduced tree species" OR "tree improvement" OR "forest genetics" OR "exotic species" OR "invasive species" OR "short rotation forestry" OR "old-growth forest" $O R$ "energy forestry" OR "forest inventory" OR "forest conversion" OR "sub alpine forest" OR "tree migration" OR "stand structure" OR "relict tree species" OR "Peripheral population" OR "marginal population" OR "relict forest" OR "genetic pollution" OR "forest tree seed" $O R$ "seedling propagation" $O R$ "forest entomology" OR "forest fragmentation" OR "forest villagers" OR "un-even aged forest" OR "Even-aged forest" OR "bio energy" OR "carbon sequestration" OR "clear cutting" OR "chain of custody" OR "ecosystem services" OR "endangered species" OR "forestland" OR "forest type" OR "forest management plan" OR "deciduous trees" OR "land use" OR "remote sensing" OR "biometry" Or "marketing" OR "multiple use" OR "pure stand" OR "mixed stand" OR "seed tree" $O R$ "seed tree cut" $O R$ "rotation period" $O R$ "seed year" $O R$ "site index" OR "conifer" OR "softwood" OR "thinning"

\section{Author Contributions}

$\mathrm{HD}$ and SA conceived, designed the research, and wrote the manuscript.

\section{Funding}

This research received no external funding.

\section{Conflicts of Interest}

The authors declare no conflict of interest.

\section{REFERENCES}

Abramo G, D'angelo CA, 2014. Assessing national strengths and weaknesses in research fields. J Informetr 8(3): 766-775. https:// doi.org/10.1016/i.joi.2014.07.002.

Anonymous, 2006. The state of science \& technology in Canada. The Committee on the State of Science \& Technology in Canada, The Council of Canadian Academies, Ottawa, Canada, Available online: https://cca-reports.ca/wp-content/uploads/2018/10/TheState-of-Science-Technology-in-Canada.pdf. (Date of accessing: 11.09.2020).

Aria M, Cuccurullo C, 2017. Bibliometrix: An R-tool for comprehensive science mapping analysis. J Informetr 11(4): 959-75. https://doi. org/10.1016/j.joi.2017.08.007.

Bastian M, Heymann S, Jacomy M, 2009. Gephi: an open source software for exploring and manipulating networks. Proceedings of the International AAAI Conference on Web and Social Media 3(1):361-362. (Date of accessing: 18.11.2020). https://ojs.aaai. org/index.php/ICWSM/article/view/13937/13786

Cameron BD, 2005. Trends in the usage of ISI bibliometric data: uses abuses and implications. Portal - Libraries and the Academy 5 (1): 105-125. https://doi.org/10.1353/pla.2005.0003.

Cetinsaya G, 2014. Büyüme, kalite, uluslararasilaşma: Türkiye yükseköğretimi için bir yol haritasi, Yükseköğretimkurulu yayın no. 2014/2, Anadolu Üniversitesi Basımevi Müdürlüğü, Eskişehir. $195 \mathrm{~s}$.

Chirici G, 2012. Assessing the scientific productivity of Italian forest researchers using the Web of Science SCOPUS and SCIMAGO databases. iForest 5: 101-107. https://doi.org/10.3832/ifor0613$\underline{005}$.

Dasdemir I, 2005. Development of a method for priority setting in forestry research projects in Turkey. Turk J Agric For 29: 211-220.

Ekizoglu A, 2001. What will be the positive and negative developments faced by forest engineering? Journal of Forest Engineering 38(5): 15-17.

Elsevier, 2013. Comparative Benchmarking of European and US Research Collaborations and Researcher Mobility. A report prepared in collaboration between Science Europe and Elsevier's SciVal Analytics September

Erdas 0,2008 . The perspective of philosophical views on education in its historical process, contemporary education and expectations from contemporary education in forestry. In: $3^{\text {rd }}$ National Forestry Congress: Forestry Education in Turkey in the 150th Year, Foresters' Association of Turkey, Ankara, Turkey, pp.15-29.
Giannetti F, Chirici G, Borghetti M, Corona P, Bucci G, 2016. Assessing the bibliometric productivity of forest scientists in Italy. Annals of Silvicultural Research 40(1): 19-30. https://doi.org/10.12899/asr1211.

Glanzel W, 2002. Co-authorship patterns and trends in the sciences (1980-1998): A bibliometric study with implications for database indexing and search strategies. Library Trends 50: 461-473.

Gumus C, 2016. Historical development of forestry education in the context of forest resources management in Turkey. Turkish Journal of Forestry 17(1): 93-98. https://doi.org/10.18182/tjf.18689.

Hazarika T, Goswswami K, Das P, 2003. Bibliometric analysis of Indian Forester: (1991-2000). IASLIC Bulletin 48(4): 213-223.

Leydesdorff L, Vaughan L, 2006. Co-occurrence matrices and their applications in information science: Extending ACA to the Web environment. J Am Soc Inf Sci Tec 57(12): 1616-1628. https://doi. org/10.1002/asi.20335.

Miah D, Shin MY, Koike M, 2013. The forestry research in Bangladesh: A bibliometric analysis of the journals published from Chittagong University, Bangladesh. Forest Science and Technology 4(2): 58-67. https://doi.org/10.1080/21580103.2008.9656339.

Milgram S, 1967. The small world problem. Psychology Today 1(1): 61-67.

Moreno JL, 1934. Who Shall Survive? Beacon House, New York, USA.

Nardi P, Di Matteo G, Palahi M, Scarascia Mugnozza G, 2016. Structure and Evolution of Mediterranean Forest Research: A Science Mapping Approach. PLoS ONE 11(5): e0155016. https:// doi.org/10.1371/journal.pone.0155016.

Newman MEJ 2001. The structure of scientific collaboration networks. Proc Natl Acad Sci USA 98(2): 404-409. https://doi. org/10.1073/pnas.021544898.

Otte E, Rousseau R, 2002. Social Network Analysis: A powerful strategy, also for the information sciences. J Inf Sci 28(6): 443-455. https://doi.org/10.1177/016555150202800601.

Ozdonmez M, Ekizoglu A, 1996. Titles and diplomas issued to graduates since the start of the forestry higher education in Turkey. Journal of the Faculty of Forestry Istanbul University 46(B): 45-64.

Peiró IG, 2018. A bibliometric analysis of the Open Access forestry research and engineering international journal-FREIJ (20172018). Forest Res Eng Int J 2(6): 320. https://doi.org/10.15406/ freij.2018.02.00066. 
Persson O, Danell R, Wiborg Schneider J, 2009. How to use Bibexcel for various types of bibliometric analysis. In: Åström F, Danell R, Larsen B, Schneider J (eds) Celebrating scholarly communication studies: A Festschrift for Olle Persson at his $60^{\text {th }}$ Birthday International Society for Scientometrics and Informetrics, Leuven, Belgium, pp. 9-24.

Rogers LF, 2002. Impact Factor: The numbers game. Am J Roentgenol 178(3): 541-542. https://doi.org/10.2214/air.178.3.1780541.

Rogers EM, 2003. Diffusion of Innovation. $5^{\text {th }}$ Edn. Free Press, New York, USA, $576 \mathrm{p}$.

Romanelli JP, Boschi RS, 2019. The legacy of Elinor Ostrom on common forests research assessed through bibliometric analysis. Cerne 25(4): 332-346. https://doi.org/10.1590/01047760201925 042658

Scott J, 2000. Social Network Analysis: A Handbook. $2^{\text {nd }}$ Edn. Sage Publications, Thousand Oaks, CA, USA, $224 \mathrm{p}$.
Sife AS, Benard R., Ernest E, 2013. Research productivity and scholarly impact of forestry researchers at Sokoine University of Agriculture: A Bibliometric Analysis. Journal of Continuing Education and Extension 4(2): 261-278.

Song Y, Zhao T, 2013. A bibliometric analysis of global forest ecology research during 2002-2011. SpringerPlus 2: 204. https://doi. org/10.1186/2193-1801-2-204.

Van Eck NJ, Waltman L, 2010. Software survey: VOSviewer, a computer program for bibliometric mapping. Scientometrics 84 : 523-538. https://doi.org/10.1007/s11192-009-0146-3.

Wagner CS, Leydesdorff L, 2005. Mapping the network of global science: Comparing international co-authorship from 1990-2000. International Journal of Technology and Globalisation 1(2): 185208. https://doi.org/10.1504/IJTG.2005.007050.

Yurdakul Erol S, Sahin G, 2016. A comparative analysis of strategic plans of forestry faculties in Turkey. FORESTIST 66(2): 497-512. doi: $\underline{\text { https://doi.org/10.17099/iffiu.76967. }}$. 